\title{
Clinical and angiographic characteristics of young Egyptian women with acute coronary syndromes
}

\begin{abstract}
Introduction: Although acute coronary syndrome (ACS) mainly occurs in individuals $>50$ years, younger adults can be affected as well. Young patients represent $2-10 \%$ of patients with ACS, most of them are men while women constitute about $25 \%$ of this population.

Methods: Patients with ACS $<45$ years were included and were subjected to history taking, clinical examination, ECG, echocardiogram, and lab investigations including cardiac enzymes, renal functions, complete blood count, lipid profile, blood sugar, complete liver functions.

Invasive management or medical management was determined depending on the diagnosis of the patient, his condition and the decision of the attending physician. For patient who underwent coronary angiography, decision of $\mathrm{PCI}$ and stenting and whether culprit lesion or complete revascularization was left for the operator.

Results: The study included 306 men and 92 women. There was no significant difference regarding hypertension, dyslipidemia, family history of ischaemic heart disease or chronic kidney disease. Diabetes was significantly higher in women $(40.2 \%)$ and body mass index was higher in women while smoking was significantly higher in men (66\%). STEMI was more in men and unstable angina more in women.
\end{abstract}

Conclusion: In Egyptian women with ACS, they have more incidence of diabetes and higher BMI compared to men with less incidence of smoking. They present more with unstable angina compared to more STEMI in men.

Keywords: acute coronary syndrome, young Egyptian women
Volume 13 Issue 3 - 2020

\author{
Timoor Hassan, Ahmed Farouk Alaarag, \\ Mahmoud Abuomar \\ Department of Cardiology, Tanta University, Egypt
}

Correspondence: Timoor Hassan, Department OF Cardiology, Tanta University, Egypt, Tel +201 I I 7495000 , Email timo_medy@yahoo.com

Received: April II, 2020 | Published: May 18, 2020
Abbreviations: ACS, acute coronary syndrome; Dm, diabetes mellitus; AMI, acute myocardial infarction; TC, total cholesterol; LDL, low-density lipoprotein; HDL, high-density lipoprotein; BMI, Body mass index

\section{Introduction}

Although acute coronary syndrome (ACS) mainly occurs in individuals $>50$ years, younger adults can be affected as well. ${ }^{1}$ In the recent decades, younger women have an increased incidence of AMI (acute myocardial infarction) which may be attributed to the increased incidence of diabetes Mellitus (DM), metabolic syndrome and also, the increased level of stress and anxiety. ${ }^{2}$ The leading cause of death in women either in USA or globally is cardiovascular disease. ${ }^{3,4}$ The care of women with cardiovascular disease especially, acute cases, show disparity even in the same income, education level and care taken. ${ }^{5}$ Different studies have used the age between 35 and 55 years as the definition of young age, so, it seems reasonable to consider 45years as the limit for young age. ${ }^{6}$ Young patients represent $2-10 \%$ of patients with ACS, most of them are men while women constitute about $25 \%$ of this population. ${ }^{7,8}$

In the context of ACS/MI gender difference do exist, some of these differences can be explained by the fact that the pathophysiological mechanisms may be different between men and women. ${ }^{5}$ The syndrome $\mathrm{X}$, in which there is evidence of myocardial ischaemia in non-invasive tests with normal coronary angiography, is more frequent in females and may be a marker of of microvascular dysfunction. Virmani et al. ${ }^{9}$ was the first to describe plaque ulceration in the setting of AMI and found it to be more common in pre-menopausal women rather than the elderly. Thrombus formation rather than obstructive CAD is more common in women than men presenting with ACS. ${ }^{10}$

AMI in absence of obstructive disease, which is more common in women, may be attributed to coronary spasm, microvascular dysfunction and spontaneous coronary artery dissection. Atypical presentation of ACS is more common in women than men, especially young ones resulting in underestimation of the severity and longer time to proper diagnosis and undertreatment. ${ }^{11-13}$ Young women with ACS represent a very special group given the protective effect of estrogen. The clinical and angiographic characteristics of this group in the Egyptian population are not well known.

\section{Methods}

This is a cross sectional observational study for patients with ACS admitted to Tanta university hospital, Elshorouk specialized hospital, IbnSina Specialized hospital between January 2017 and May 2019. A total of 3312 patients with acute coronary syndrome were admitted, of which 430 were $45 y$ years or less and women were 116 patients. Of 116 women only 92 patients accepted to participate in the study and informed consent was taken for participation in the study.

Acute coronary syndromes include all patients presenting with ST segment elevation myocardial infarction (STEMI), Non-ST segment elevation myocardial infarction (NSTEMI) and unstable angina 
patients. STEMI was defined according to ACCF/AHA guidelines as "new ST-segment elevation at the J-point in at least 2 contiguous leads $=2 \mathrm{~mm}$ in men, $=1.5 \mathrm{~mm}$ in women in leads V2 to $\mathrm{V} 3$, or $=1 \mathrm{~mm}$ in other contiguous chest leads or the limb leads." ${ }^{14}$ As per the ACC/ AHA guideline statement, the absence of ST elevation on ECG with typical symptoms of angina identifies the patients as having non-ST segment elevation -ACS. The latter, can be subdivided based on the results of cardiac biomarkers. If elevated and the clinical context is appropriate, the patient is considered to have NSTEMI; otherwise, the patient is diagnosed as unstable angina. All patients underwent history taking, clinical examination, ECG, echocardiogram, and lab investigations including cardiac enzymes, renal functions, complete blood count, lipid profile, blood sugar, complete liver functions.

Hypertension was defined as having a history of hypertension or systolic/diastolic blood pressure $\geq 140 / 90 \mathrm{mmHg}$. Diabetes (type 1 or 2) was defined as history of diabetes or fasting plasma glucose $>126 \mathrm{mg} / \mathrm{dL}$. We used low-density lipoprotein (LDL) $(>130 \mathrm{mg} / \mathrm{dL})$, total cholesterol (TC) $(>200 \mathrm{mg} / \mathrm{dL})$, and high-density lipoprotein (HDL) $(<40 \mathrm{mg} / \mathrm{dL})$ as cut off values to diagnose dyslipidemia as defined in the NCEP/ATP 3 guidelines. Body mass index (BMI) was calculated as weight $(\mathrm{kg}) /$ height squared $\left(\mathrm{m}^{2}\right)$. Patients were considered overweight or obese if they had a BMI of 25-29.9 or $\geq 30 \mathrm{~kg} / \mathrm{m}^{2}$ respectively. Invasive or medical strategy was based on the diagnosis of the patient, his condition and the decision of the attending physician. In patients who underwent coronary angiography, decision of PCI and stenting and whether culprit-lesion only or complete revascularization was left for the operator.

\section{Results}

Table 1 shows comparison between males and females regarding the risk factors for coronary artery disease, where females tend to have stress more than males before the attack $(31 \%$ of male and $41.3 \%$ of females with $p$ value 0.06 ). There was no significant difference regarding hypertension $(39.2 \%$ of males and $46.7 \%$ of females), dyslipidemia ( $40.8 \%$ for males and $47.8 \%$ for females), family history of ischaemic heart disease $(33 \%$ for male and $35.9 \%$ for females) and CKD (1.3\% of males and $2.2 \%$ of females) between males and females. There was a significant difference between females and males regarding the incidence of diabetes which was $40.2 \%$ in females and $29.1 \%$ in males with a p value of 0.044 . Similarly, BMI was significantly higher in females than males with the incidence of overweight and obese patients in females $38 \%$ and $43.3 \%$ respectively while it was $34 \%$ and $32 \%$ in males respectively with a $p$ value of 0.014 .

Table I Comparison between males and females regarding the traditional risk factors

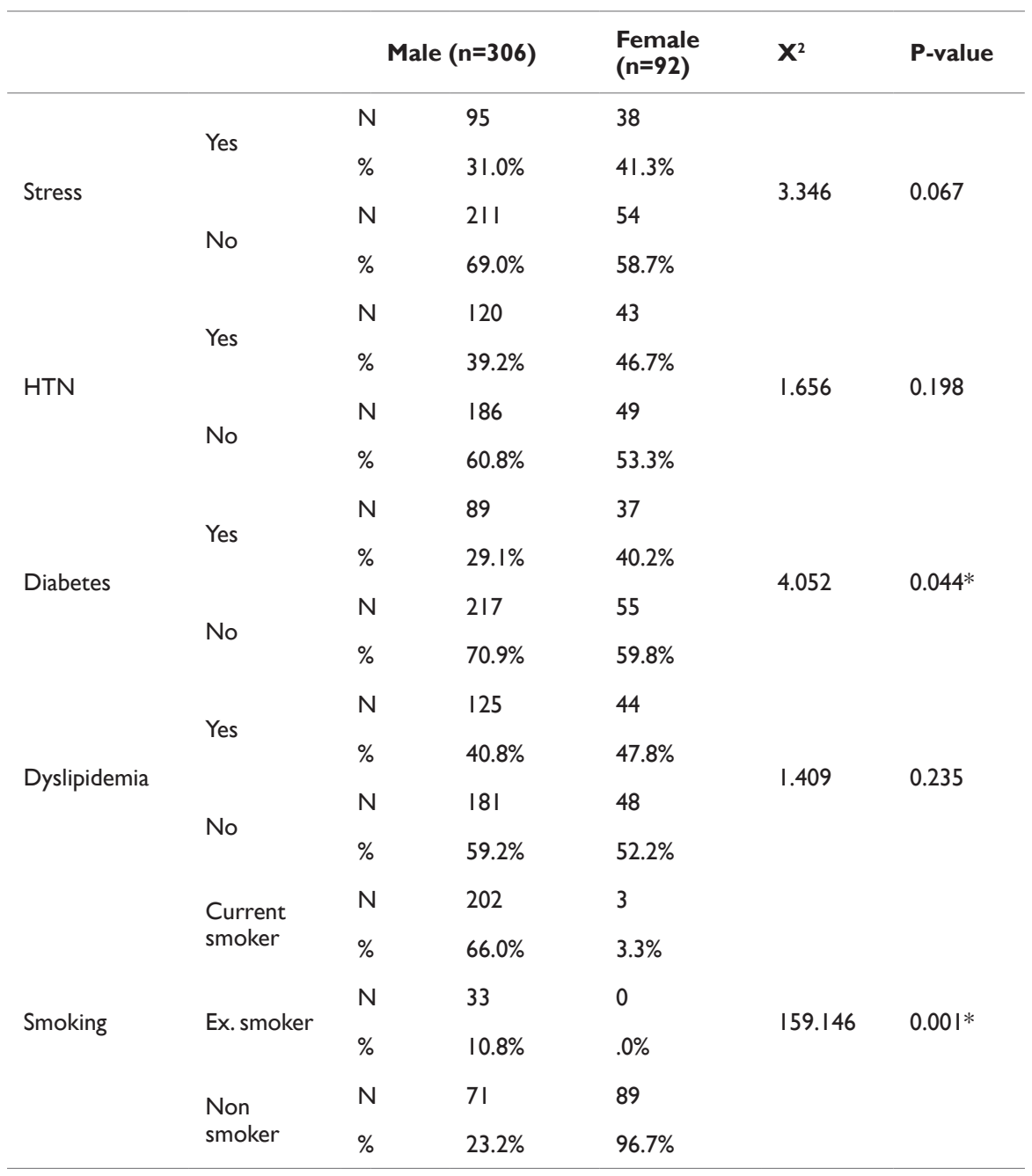




\begin{tabular}{|c|c|c|c|c|c|c|}
\hline & & \multicolumn{2}{|c|}{ Male $(n=306)$} & \multirow{2}{*}{$\begin{array}{l}\begin{array}{l}\text { Female } \\
(\mathbf{n = 9 2})\end{array} \\
33\end{array}$} & \multirow[t]{2}{*}{$\mathbf{X}^{2}$} & \multirow[t]{2}{*}{ P-value } \\
\hline \multirow{4}{*}{$\mathrm{FH}$ IHD } & \multirow{2}{*}{ Yes } & $\mathrm{N}$ & 101 & & & \\
\hline & & $\%$ & $33.0 \%$ & $35.9 \%$ & \multirow{3}{*}{0.260} & \multirow{3}{*}{0.610} \\
\hline & \multirow{2}{*}{ No } & $\mathrm{N}$ & 205 & 59 & & \\
\hline & & $\%$ & $67.0 \%$ & $64.1 \%$ & & \\
\hline \multirow{6}{*}{ BMI } & \multirow{2}{*}{ Normal } & $\mathrm{N}$ & 104 & 17 & \multirow{6}{*}{8.605} & \multirow{6}{*}{$0.014^{*}$} \\
\hline & & $\%$ & $34.0 \%$ & $18.5 \%$ & & \\
\hline & Over & $\mathrm{N}$ & 104 & 35 & & \\
\hline & weight & $\%$ & $34.0 \%$ & $38.0 \%$ & & \\
\hline & \multirow{2}{*}{ Obese } & $\mathrm{N}$ & 98 & 40 & & \\
\hline & & $\%$ & $32.0 \%$ & $43.5 \%$ & & \\
\hline \multirow{4}{*}{ CKD } & \multirow{2}{*}{ Yes } & $\mathrm{N}$ & 4 & 2 & \multirow{4}{*}{0.358} & \multirow{4}{*}{0.550} \\
\hline & & $\%$ & $1.3 \%$ & $2.2 \%$ & & \\
\hline & \multirow{2}{*}{ No } & $\mathrm{N}$ & 302 & 90 & & \\
\hline & & $\%$ & $98.7 \%$ & $97.8 \%$ & & \\
\hline
\end{tabular}

The incidence of smoking was significantly higher in males than females with $66 \%$ of males were current smokers compared to 3.3 of females with a $\mathrm{p}$ value of 0.001 . There was no significant difference between females and males regarding the presenting symptom of the ACS, despite the fact that more females present with palpitation $(18.5 \%$ vs $12.7 \%$ ), dyspnoea ( $37 \%$ vs $29.4 \%$ ) and dizziness/confusion ( 5.4 vs
3.6\%), compared to males Table 2 . There was a trend for STEMI to be the presenting condition in males than females ( $46.1 \%$ vs $35.9 \%)$ with a $\mathrm{p}$ value of 0.08 , while there was no significant difference regarding NSTEMI (31\% vs $29.3 \%)$. Unstable angina was the most frequent presenting symptom in females and was significantly higher than males $(34.8 \%$ vs $22.9 \%)$ with a p value of 0.022 , Table 3 .

Table 2 Comparison between males and females regarding the presenting symptoms

\begin{tabular}{|c|c|c|c|c|c|c|}
\hline & & & $\begin{array}{l}\text { Male } \\
(n=306)\end{array}$ & $\begin{array}{l}\text { Female } \\
(n=92)\end{array}$ & $\mathbf{X}^{2}$ & P-value \\
\hline \multirow{4}{*}{ Chest pain } & \multirow{2}{*}{ Yes } & $\mathrm{N}$ & 285 & 83 & \multirow{4}{*}{0.865} & \multirow{4}{*}{0.352} \\
\hline & & $\%$ & $93.1 \%$ & $90.2 \%$ & & \\
\hline & \multirow{2}{*}{ No } & $\mathrm{N}$ & 21 & 9 & & \\
\hline & & $\%$ & $6.9 \%$ & $9.8 \%$ & & \\
\hline \multirow{4}{*}{ Dyspnoea } & \multirow{2}{*}{ Yes } & $\mathrm{N}$ & 90 & 34 & \multirow{4}{*}{1.887} & \multirow{4}{*}{0.171} \\
\hline & & $\%$ & $29.4 \%$ & $37.0 \%$ & & \\
\hline & \multirow{2}{*}{ No } & $\mathrm{N}$ & 216 & 58 & & \\
\hline & & $\%$ & $70.6 \%$ & $63.0 \%$ & & \\
\hline \multirow{4}{*}{ Palpit } & \multirow{2}{*}{ Yes } & $\mathrm{N}$ & 39 & 17 & \multirow{4}{*}{1.923} & \multirow{4}{*}{0.166} \\
\hline & & $\%$ & $12.7 \%$ & $18.5 \%$ & & \\
\hline & \multirow{2}{*}{ No } & $\mathrm{N}$ & 267 & 75 & & \\
\hline & & $\%$ & $87.3 \%$ & $81.5 \%$ & & \\
\hline \multirow{4}{*}{ Dizz/Confusion } & \multirow{2}{*}{ Yes } & $\mathrm{N}$ & 11 & 5 & \multirow{4}{*}{0.621} & \multirow{4}{*}{0.431} \\
\hline & & $\%$ & $3.6 \%$ & $5.4 \%$ & & \\
\hline & \multirow{2}{*}{ No } & $\mathrm{N}$ & 295 & 87 & & \\
\hline & & $\%$ & $96.4 \%$ & $94.6 \%$ & & \\
\hline
\end{tabular}


Table 3 Comparison between males and females regarding the type of ACS

\begin{tabular}{|c|c|c|c|c|c|c|}
\hline & & \multicolumn{2}{|c|}{ Male $(n=306)$} & \multirow{2}{*}{$\begin{array}{l}\text { Female }(n=92) \\
33\end{array}$} & \multirow{2}{*}{$\begin{array}{l}\mathbf{X}^{2} \\
3.001\end{array}$} & \multirow[t]{2}{*}{ P-value } \\
\hline \multirow{6}{*}{ ACS } & \multirow[b]{2}{*}{ STEMI } & $\mathrm{N}$ & $|4|$ & & & \\
\hline & & $\%$ & $46.1 \%$ & $35.9 \%$ & & 0.083 \\
\hline & \multirow[b]{2}{*}{ NSTEMI } & $\mathrm{N}$ & 95 & 27 & \multirow[b]{2}{*}{0.102} & \multirow[b]{2}{*}{0.757} \\
\hline & & $\%$ & $31.0 \%$ & $29.3 \%$ & & \\
\hline & \multirow[b]{2}{*}{ UA } & $\mathrm{N}$ & 70 & 32 & \multirow[b]{2}{*}{5.259} & \multirow[b]{2}{*}{$0.022^{*}$} \\
\hline & & $\%$ & $22.9 \%$ & $34.8 \%$ & & \\
\hline
\end{tabular}

There was no difference regarding the location of STEMI between females and males with $54.5 \%$ of females presented with anterior STEMI vs $58.2 \%, 6.1 \%$ of females presented with lateral STEMI vs $7.8 \%$ and $39.4 \%$ presented with inferior STEMI compared to $34 \%$, Table 4. Table 5 shows no significant difference between females and males regarding the management strategy of STEMI group of patients where $54.5 \%$ of females were managed with PPCI vs $62.4 \%$ of males, $27.3 \%$ received fibrinolytic therapy vs $22.7 \%$ and $18.2 \%$ received neither vs $14.9 \%$. In the group of patients with NSTEMI/

Table 4 Comparison between males and females regarding the type of STEMI
UA, we found that females are more significantly receiving PCI than males $(52.4 \%$ vs $28.5 \%)$, but because of the small sample volume of this group (21 patients of which 11 had PCI) this result can be discarded. There was no significant difference between females and males who underwent coronary angiography regarding the number of vessels affected but more females have normal or no-significant lesions $(33.3 \%$ vs $27.8 \%)$ with no significant difference. In patients with single vessel CAD, there was no difference between females and males regarding the affected vessel, where in both LAD was the most commonly affected vessel (62.5\% vs 64.8$)$.

\begin{tabular}{|c|c|c|c|c|c|c|}
\hline & & & ale $(n=|4|)$ & Female $(n=33)$ & $\mathbf{X}^{2}$ & $P$-value \\
\hline \multirow{6}{*}{ STEMI } & \multirow{2}{*}{ Ant. } & $\mathrm{N}$ & 82 & 18 & \multirow{6}{*}{0.388} & \multirow{6}{*}{0.824} \\
\hline & & $\%$ & $58.2 \%$ & $54.5 \%$ & & \\
\hline & \multirow{2}{*}{ Lat. } & $\mathrm{N}$ & II & 2 & & \\
\hline & & $\%$ & $7.8 \%$ & $6.1 \%$ & & \\
\hline & \multirow{2}{*}{ Inferior } & $\mathrm{N}$ & 48 & 13 & & \\
\hline & & $\%$ & $34.0 \%$ & $39.4 \%$ & & \\
\hline
\end{tabular}

Table 5 Comparison between males and females regarding the management of STEMI

\begin{tabular}{|c|c|c|c|c|c|c|}
\hline & & & $(n=|4|)$ & Female $(n=33)$ & $\mathbf{x}^{2}$ & P-value \\
\hline \multirow{7}{*}{ Management } & \multirow{2}{*}{$\mathrm{PPCl}$} & $\mathrm{N}$ & 88 & 18 & \multirow{7}{*}{0.696} & \multirow{7}{*}{0.706} \\
\hline & & $\%$ & $62.4 \%$ & $54.5 \%$ & & \\
\hline & \multirow{3}{*}{ Fibrinolytic therapy } & $\mathrm{N}$ & 32 & 9 & & \\
\hline & & & & & & \\
\hline & & $\%$ & $22.7 \%$ & $27.3 \%$ & & \\
\hline & \multirow{2}{*}{ Neither } & $\mathrm{N}$ & 21 & 6 & & \\
\hline & & $\%$ & $14.9 \%$ & $18.2 \%$ & & \\
\hline
\end{tabular}

\section{Discussion}

Ischaemic heart disease represents a major public health problem in the modern world. Only a small percentage $(<10 \%)$ of patients are below the age of 45 years. ${ }^{15,16}$ In developed countries, the actual prevalence of the disease, in men and women in the age group $35-44$ years was found to be $0.5 \%$ and $0.18 \%$, respectively. There are many underlying mechanisms such as rupture of a vulnerable plaque or erosion of the endothelial layer, hypercoagulable states, coronary artery spasm, inflammation, etc. Atherosclerosis remains the major cause of ACS in the young ${ }^{17}$ Atherosclerosis may begin as early as the first decade of life and considerable lesions in coronary arteries may be apparent by the age of 25-30 years. ${ }^{18}$

Approximately $10 \%$ of patients with ST-segment-elevation myocardial infarction (STEMI) were young patients and $2 \%$ of these patients were wome. ${ }^{1}$ Our study conducted in the young Egyptian population presented with ACS showed that $26.9 \%$ of patients were females. Diabetes and higher BMI were significantly higher in females than males while smoking was significantly higher in males. Chest pain was the main presenting symptom in both young men and women, despite palpitation; dizziness and dyspnoea were more frequent in women. STEMI was more common as the presenting 
symptom in men while unstable angina was the main presenting symptom in women. Women tend to have more stress before the event than their men counterparts. There was no difference between both groups regarding the location or the management strategy for STEMI (62.4\% vs $54.5 \%$ of men and women received primary PCI as the management strategy, respectively).

In patients with single vessel disease LAD was the most commonly affected vessel in both men and women $(64.5 \%$ vs $62.8 \%)$. More women had PCI in the NSTEMI/UA group than males $(52.4 \%$ vs $28.5 \%$ ) which can be explained by the fact that the number of women in this group was very small, only 21 women of which 11 had PCI. Ricci B et al., ${ }^{1}$ found that smoking and high BMI are independent risk factors in the young which is similar to our results but in the Egyptian population, smoking was significantly higher in males than females and BMI was significantly higher in women than men. In accordance with our results, they observed less frequency of multi-vessel disease (it was $9.5 \%$ in men and $7.7 \%$ in women in our study). Similarly, the left anterior descending artery (LAD) was the most commonly affected vessel.

Nagamalesh UM et al. ${ }^{14}$ studied the clinical criteria of young Indian women presenting with ACS, they similarly found an incidence of about $40 \%$ of diabetes and unlike our results they found a high incidence of dyslipidemia in young Indian women reaching around $70 \%$ compared to $47 \%$ in our study and both studies showed low incidence of smoking and CKD in young women with ACS. Chest pain was the main presenting symptom like our study. Most of patients with STEMI received primary PCI and LAD was the most commonly affected vessel, which is similar to our findings.

The INTERHEART study ${ }^{19}$ found that young women with myocardial infarction are more likely to be smokers, diabetics, hypertensive with abdominal obesity while our study showed young women with ACS have more diabetes, and higher BMI but less likely to be smokers than men. El-Husainy $\mathrm{F}$ et al. ${ }^{20}$ conducted a study in Saudi young population presented with ACS, they found that smoking and dyslipidemia are common risk factors in the young (smoking was significantly higher in young men than young women in our study) and STEMI was more common than NSTEMI which is similar to our results. Likewise, they found that LAD is the most commonly affected vessel and normal coronary arteries were found in $23 \%$ of patients ( $28 \%$ in men and $33 \%$ of women in our study).

Bhardwaj $\mathrm{R}$ et al. ${ }^{21}$ examined young patients with myocardial infarction and found that smoking, hypertension, dyslipidemia are common risk factors in this group of patients and only one out of 124 patients was female (116 females out of total of 430 in our study) and they also had $10 \%$ of patients with normal coronary arteries compared to $28 \%$ of males and $33 \%$ of females in our study and similarly LAD was the most commonly affected artery.

\section{Conclusion}

ACS in the young Egyptian population is a rising problem, and identification of the risk factors and proper patient evaluation and early diagnosis can help to reduce its burden. Smoking in males and high BMI in females are the most common risk factors in this young group of patients.

\section{Acknowledgments}

None.

\section{Conflicts of interest}

The authors declare there are no conflicts of interest related to the article.

\section{Funding}

None.

\section{References}

1. Ricci B, Cenko E, Vasiljevic Z et al. Acute coronary syndrome: the risk to young women. J Am Heart Assoc. 2017;6:1-11.

2. Chandrasekhar J, Gill A, Mehran R. Acute myocardial infarction in young women: current perspectives. International Journal of Women's Health. 2018;10:267-284.

3. Mozaffarian D, Benjamin EJ, Go AS, et al. on behalf of the American Heart Association Statistics Committee and Stroke Statistics Subcommittee. Heart disease and stroke statistics - 2015 update: a report from the American Heart Association. Circulation. 2015;131:e29-e322.

4. Gholizadeh L, Davidson P. More similarities than differences: an international comparison of CVD mortality and risk factors in women. Health Care Women Int. 2008;29:3-22.

5. Graham G. Acute coronary syndromes in women: Recent treatment trends and outcomes. Clinical Medicine Insights: Cardiology. 2016;10:1-10.

6. Beckowski M. Acute coronary syndromes in young women-the scale of the problem and the associated risks. Kardiochirurgia I Torakochirurgia Polska. 2015;12(2):134-138.

7. Doughty M, Mehta R, Bruckman D, et al. Acute myocardial infarction in the young-The University of Michigan experience. Am Heart J. 2002;143:56-62.

8. Chua SK, Hung HF, Shyu KG, et al. Acute ST-elevation myocardial infarction in young patients: 15 years of experience in a single center. Clin Cardiol. 2010;33(3):140-148.

9. Falk E, Nakano M, Bentzon JF, et al. Update on acute coronary syndromes: the pathologists' view. Eur Heart J. 2013;34(10):719-728.

10. Pepine CJ, Ferdinand KC, Shaw LJ, et al. ACC CVD in Women Committee. Emergence of nonobstructive coronary artery disease: a woman's problem and need for change in definition on angiography. $\mathrm{J} \mathrm{Am}$ Coll Cardiol. 2015;66(17):1918-1933.

11. Benamer $\mathrm{H}$, Bataille $\mathrm{S}$, Tafflet $\mathrm{M}$, et al. Longer pre-hospital delays and higher mortality in women with STEMI: the e-MUST Registry. Euro Intervention. 2016;12(5): e542-e549.

12. Cheng CI, Yeh KH, Chang HW, et al. Comparison of baseline characteristics, clinical features, angiographic results, and early outcomes in men vs women with acute myocardial infarction undergoing primary coronary intervention. Chest. 2004;126:47-53.

13. Nguyen HL, Saczynski JS, Gore JM, et al. Age and sex differences in duration of prehospital delay in patients with acute myocardial infarction: a systematic review. Circ Cardiovasc Qual Outcomes. 2010;3:82-92.

14. Nagamalesh UM, Abhinay T, Naidu KC, et al. Clinical profile of young Indian women presenting with acute coronary syndrome. J Clin Prev Cardiol. 2018;7:106-110.

15. Zimmerman FH, Cameron A, Fisher LD, et al. Myocardial infarction in young adults: Angiographic characterization, risk factors and prognosis (Coronary artery surgery study registry). J Am Coll Cardiol. $1995 ; 26: 654-661$

16. Choudhury L, Marsh JD. Myocardial infarction in young patients. Am J Med. 1999;107:254-261. 
17. Tuzcu E, Kapadia S, Tutar E, et al. High prevalence of coronary atherosclerosis in asymptomatic teenagers and young adults: evidence from intravascular ultrasound. Circulation. 2001;103(22):2705-2710.

18. Al-Nozha MM, Arafah MR, Al-Mazrou YY, et al. Coronary artery disease in Saudi Arabia. Saudi Med J. 2004;25(9):1165-1171.

19. Anand SS, Islam S, Rosengren A, et al. INTERHEART Investigators. Risk factors for myocardial infarction in women and men: insights from the INTERHEART study. Eur Heart J. 2008;29(7):932-940.
20. Al-Husainy F, Alamry B, Alyami A et al. Acute coronary syndrome among young patients in Saudi Arabia (single centre study). J Cardiol Curr Res. 2019;12(3):60-63.

21. Bhardwaj R, Kandoria A, Sharma R. Myocardial infarction in young adults-risk factors and pattern of coronary artery involvement. Niger Med J. 2014;55(1):44-47. 